\title{
2q23.1 microduplication syndrome
}

INSERM

\section{Source}

INSERM. (1999). Orphanet: an online rare disease and orphan drug data base. 2 q23.1 microduplication syndrome. ORPHA:313947

2q23.1 microduplication syndrome is a rare chromosomal anomaly syndrome, resulting from the partial duplication of the long arm of chromosome 2, primarily characterized by global developmental delay, hypotonia, autistic-like features and behavioural problems. Craniofacial dysmorphism (arched eyebrows, hypertelorism, bilateral ptosis, prominent nose, wide mouth, micro/retrognathia) and an affable personality are also commonly associated. Minor digital anomalies (fifth finger clinodactyly and large, broad first toe) have occasionally been reported. 